\title{
Effect of lactulose on cerebral metabolism in patients with chronic portosystemic encephalopathy
}

\author{
I. M. JAMES AND M. GARASSINI \\ From the Department of Medicine, Royal Free Hospital, London
}

SUMmARY Cerebral blood flow and cerebral metabolism were studied in six patients with moderately severe portosystemic encephalopathy before and after a 10-day course of lactulose. As a result of therapy there was a mean increase in cerebral oxygen utilization but no changes in either mean glucose consumption or in mean cerebral blood flow. It appears therefore that the abnormalities in cerebral metabolism that have been previously described in patients with hepatic encephalopathy can be improved by the oral administration of lactulose.

In patients with severe hepatic encephalopathy there is a fall in cerebral blood flow and in cerebral oxygen consumption (Fazekas, Ticktin, Ehrmantraut, and Alman, 1956; Posner and Plum, 1960) together with an abnormality in the handling of glucose by the brain (James, Nashat, Sampson, Williams, and Garassini, 1969). Since clinical impressions of improvement are difficult to evaluate and to quantitate, these metabolic changes can be used as an index of the efficacy of various forms of treatment. Cerebral metabolic studies have already been used by us for the assessment of various forms of treatment, namely, the effect of induced metabolic alkalosis on hepatic encephalopathy (James et al, 1969) and for the assessment of extracorporeal pig's liver perfusion in hepatic coma (Parbhoo, Kennedy, James, Chalstrey, Ajdukiewicz, Brook, Xanalatas, Soyer, and Sherlock, 1971).

The rates of cerebral oxygen and glucose consumption were studied in six patients with moderately severe portosystemic encephalopathy before and after a 10-day course of oral lactulose $(60 \mathrm{ml}$ of $50 \% \mathrm{w} / \mathrm{w}$ solution per day).

All the patients studied had evidence of chronic liver disease and of some neurological abnormality as characterized by a flapping tremor, exaggeration of the deep tendon reflexes, or somnolence. Grade 1 or grade 2 changes were seen in the electroencephalogram. No change in therapy or diet was made one week before the study or during the 10-day period of the study.

\section{Methods}

CEREBRAL BLOOD FLOW

Cerebral blood flow was measured by the inhalation Received for publication 24 June 1971. of radioactive ${ }^{133}$ Xenon according to the method of Mallett and Veall (1965). Corrections for arterial recirculation of the gas were made by monitoring the radioactivity of the end tidal air. Subsequent deconvolutional analysis of the cerebral decay curve into three components was performed with an analogue computer (Crawley, 1968). The bloodbrain partition coefficients for Xenon used in the calculation of cerebral blood flow were those of Mallett and Veall.

Arterial blood was obtained by puncture of the femoral artery and cerebral venous blood by jugular bulb puncture. Oxygen content was measured by an oxygen electrode technique (Linden, Ledsome, and Norman, 1965) and glucose by a glucose oxidase method.

$p \mathrm{H}, \mathrm{pCO}_{2}$, and $\mathrm{pO}_{2}$ were measured with the appropriate Radiometer electrodes.

\section{Results}

\section{CLINICAL IMPROVEMENT}

In five out of the six patients clinical improvement was noted (Table I). This was most obvious in patients 1 and 2 who had the severest encephalopathy with some degree of drowsiness.

Most patients recognized an improvement in themselves but this was marred by a troublesome diarrhoea in three patients. Two of these patients returned to neomycin therapy after the study and one (patient 3) appeared to require no therapy other than protein restriction.

Patient 4, who had impaired renal function as well as liver disease, showed some improvement on lactulose therapy. 


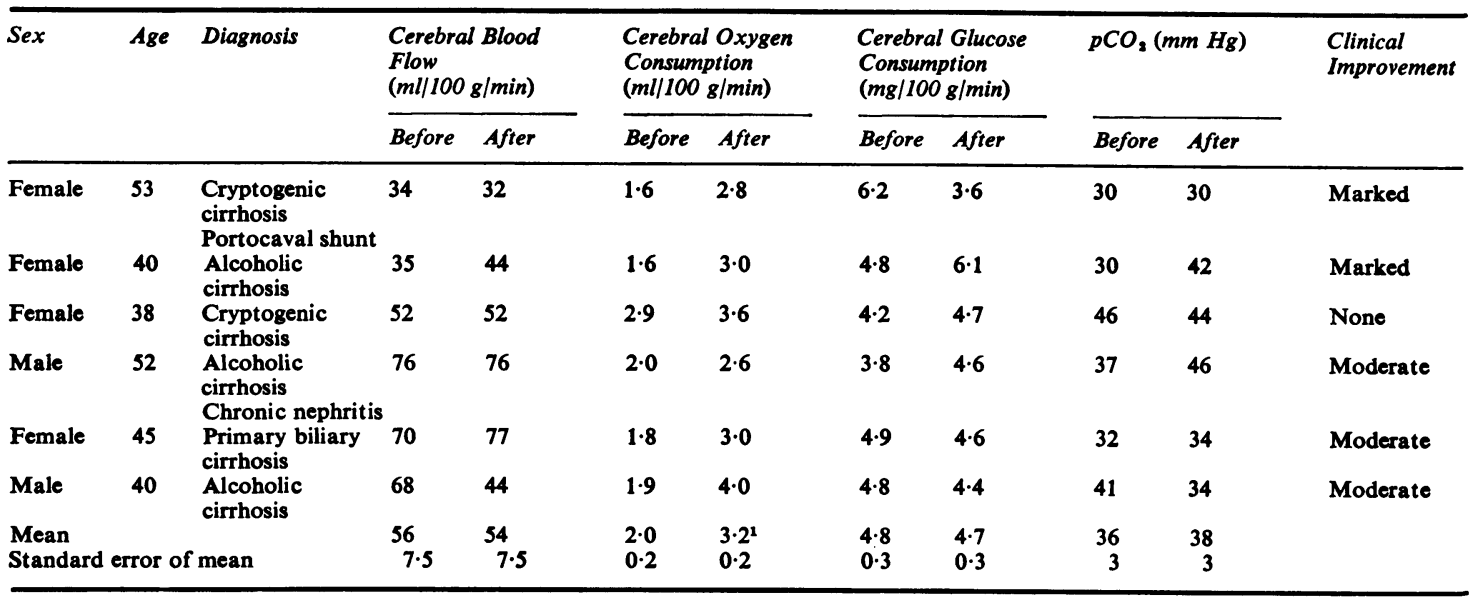

Table I Effect of 10 days' lactulose therapy on cerebral metabolism in patients with chronic portosystemic encephalopathy

${ }^{1}$ Significantly different from control value at $5 \%$ level.

CEREBRAL BLOOD FLOW

A very wide scatter in values from $34 \mathrm{ml} / 100 \mathrm{~g} / \mathrm{min}$ to $76 \mathrm{ml} / 100 \mathrm{~g} / \mathrm{min}$ was found in these patients. Lactulose therapy did not occasion a change in most instances. There was a fall in cerebral blood flow in patient 6 , but a concurrent fall in arterial $\mathrm{pCO}_{2}$ may well have been responsible for this change.

\section{CEREBRAL METABOLISM}

In all patients there was an increase in cerebral oxygen consumption. Since there was no commensurate increase in cerebral blood flow it can be seen that this increase was due to an increased arterial venous difference in oxygen content. There was no consistent change in cerebral glucose consumption, however, but an improvement in most cases of the oxygen glucose index. If this index is calculated, in the conventional way as

$$
\frac{\mathrm{A}-\mathrm{V} \mathrm{O}_{2}(\mathrm{~m} \text { mole }) \times 100 \%}{6 \times \mathrm{A}-\mathrm{V} \text { glucose }(\mathrm{m} \text { mole })}
$$

then a mean value of $49 \%$ increased to a value of $80 \%$ as a result of therapy.

These changes in cerebral metabolism were not accompanied by significant changes in arterial $\mathrm{pCO}_{2}$ or in arterial hydrogen ion concentration.

\section{Discussion}

It was a surprise to find that despite a low oxygen consumption before treatment in these patients cerebral blood flow was normal or even slightly high. The normal value for cerebral blood flow in our hands in $48.0 \mathrm{ml} \pm 2.0$ (SEM). Certainly this group of patients with portosystemic encephalopathy had a much higher mean flow than the patients with hepatic encephalopathy previously described by us of $35 \mathrm{ml} / 100 \mathrm{~g} / \mathrm{min} \pm 3$ (SEM) (James et al, 1969). However, Polli and his colleagues (Polli, Porro, and Maiolo, 1969) have shown that immediately after a portosystemic shunt there is an increase in cerebral blood flow. This is at a time before the patient exhibits clinical signs of encephalopathy. Once the neurological signs become manifest, brain oxygen consumption falls and there is presumably a secondary fall in cerebral blood flow. The time sequence of these events has, however, never been studied in patients.

The high cerebral blood flow noted on this occasion may be due to the fact that this group of patients was not as ill as that previously studied and the depression in oxygen consumption not yet as marked. It is certainly true that those patients, namely, patients 1 and 2, who had the lowest cerebral oxygen consumption also had the lowest flows. The very high values for cerebral blood flow noted in patient 4 may be in part due to the fact that he had some degree of renal failure in addition to liver disease.

It has been suggested that the beneficial action of lactulose in patients with portosystemic encephalopathy may be due either to the suppression of ammonia-forming organisms in the gut (Bircher, Muller, Guggerheim, and Haemmerli, 1966) or to a decrease in absorption of ammonia from the intestines as the result of an increased hydrogen ion gradient (Summerskill, Aoyagi, and Evans, 1966). However, it 
can be as easily argued that lactulose could reduce the formation of many other toxic products from bacterial protein breakdown in the gut and that the $p \mathrm{H}$ gradient would also reduce the absorption of any toxin of a weak base

Whatever the mode of action of lactulose in patients with portosystemic encephalopathy there would appear to be no doubt that the administration of lactulose is able to reverse at least partially the abnormalities in cerebral metabolism.

We wish to thank Professor Sheila Sherlock for her helpful advice and encouragement. This work was supported by an M.R.C. grant to one of us (I.M.J.).

References

Bircher, J., Müller, J., Guggenheim, P., and Haemmerli, U. P. (1966). Treatment of chronic portal-systemic encephalopathy with lactulose. Lancet, 1, 890-892.
Crawley, J. C. W. (1968). An analogue computer for calculating blood perfusion rates. Bio-Med. Eng., 3, 256-261.

Fazekas, J. F., Ticktin, H. E., Ehrmantraut, W. R., and Alman, R. W. (1956). Cerebral metabolism in hepatic insufficiency. Amer. $J$. Med., 21, 843-849.

James, I. M., Nashat, S., Sampson, D., Williams, H. S., and Garassini, M. (1969). Effect of induced metabolic alkalosis in hepatic encephalopathy. Lancet, 2, 1106-1108.

Linden, R. J., Ledsome, J. R., and Norman, J. (1965). Simple methods for the determination of the concentrations of carbon dioxide and oxygen in blood. Brit. J. Anaesth., 37, 77-88.

Parbhoo, S. P., Kennedy, J., James, I. M., Chalstrey, L. J., Ajdukiewicz, A., Brook, P. J., Xanalatas, C., Soyer, P., and Sherlock, S. (1971). Extracorporeal pig-liver perfusion in treatment of hepatic coma due to fulminant hepatitis. Lancet, $1,659-665$.

Polli, E., Bianchi Porro, G., and Maiolo, A. T. (1969). Cerebral metabolism after portacaval shunt. Lancet, $1,153$.

Posner, J. B., and Plum, F. (1960). The toxic effects of carbon dioxide and acetazolamide in hepatic encephalopathy. J. clin. Invest. $39,1246-1258$.

Summerskill, W. H. J. Aoyagi, T, and Evans, W. B. (1966). Ammonia in the upper gastrointestinal tract of man: quantitations and relationships. Gut, 7, 497-501.

Mallett, B. L., and Veall, N. (1965). The measurement of regional cerebral clearance rates in man using Xenon-133 inhalation and extracranial recording. Clin. Sci., 29, 179-191. 